\title{
NOTÍCIA DA ATUAL LITERATURA BRASILEIRA DIGITAL ${ }^{1}$
}

\author{
Alckmar Luiz dos Santos - CNPq, NuPILL (UFSC) \\ alckman@gmail.com \\ Cristiano de Sales - CNPq, NuPILL (UFSC) \\ cristianomupill@yahoo.com.br
}

Se examinamos o que se faz atualmente no Brasil, sob a denominação de literatura digital, vamos encontrar um conjunto heterogêneo não só de criações, mas também de exercícios de crítica e de tentativas de teorização. Se heterogeneidade é natural e enriquecedora, do lado da criação artística, pode ser redutora e paralisante do lado da estética. E se nossa tentativa aqui implica justamente tecer comentários e considerações acerca desse quadro todo, duas posturas se impõem e são mesmo incontornáveis:

1. É preciso sistematizar e categorizar minimamente isso que se vem chamando literatura digital brasileira, sob pena de cairmos numa crítica impressionista ou improvisada, dessas feitas ao sabor do acaso ou, pior ainda, movidas por relações pessoais.

2. A partir, assim, dessa sistematização mínima inicial, se deve apontar o que seria valioso, de um lado, e, de outro, o que seria limitado e mal feito. Para isso, é evidente que se terá de hierarquizar os objetos sob análise, a partir de pressupostos artísticos e estéticos claramente estabelecidos.

Do que foi dito acima, depreende-se facilmente que fazer crítica literária é, dentre outras coisas, não se furtar ao julgamento de valor, ao contrário do que se vê com freqüência. De fato, uma hesitação temerosa tomou conta da crítica (e não só a das artes literárias), a partir de certo momento no século passado. Pretendemos, neste trabalho, fazer exatamente o oposto: no que se refere à criação digital brasileira, queremos não só falar do que tem sido feito nos últimos anos, mas apontar as propostas mais interessantes e, talvez, as mais problemáticas. De outro lado, é até um truísmo afirmar que, quando a crítica tem por objeto a produção contemporânea, as dificuldades aumentam, por não se dispor, para isso, de balizas e

\footnotetext{
1 Advertência: este é um trabalho para ser lido conectado à internete. É a única maneira de o leitor verificar, por sua própria conta, boa parte do que escrevemos aqui.
} 
de apoios de tradições críticas anteriores. Nesse caso, cabe ao crítico andar mesmo na cordabamba, correndo o risco de cair a cada instante. Sem isso, não há leitura, não há aprendizado, não se avança com os métodos de crítica e, também, pouco se ajuda as técnicas de criação a avançarem.

Nos últimos vinte anos (ou quase isso), em nossa literatura, as escritas digitais têm proposto algumas criações que não deixam de encetar um diálogo com diferentes tradições literárias, por mais precário que seja, às vezes, esse diálogo. Mas não apenas isso: elas também têm ajudado a refletir acerca das reconfigurações que afetam as criações literárias todas, por força do intenso contato com as tecnologias contemporâneas, sobretudo as digitais. Temos aí, exposto de modo evidente, uma intersecção de espaços culturais bastante heterogêneos (estamos falando da criação verbal e da tecnologia informática), o que traz um problema que poderia ser assim formulado:

Como compatibilizar as técnicas e os materiais literários hoje disponiveis, com as tecnologias digitais hodiernas, tanto do lado da criação, quanto do lado da crítica?

É importante ressaltar que, quando falamos de técnicas e materiais literários hoje disponiveis, estamos nos referindo a qualquer elemento literário que esteja ao alcance dos criadores, não importando quão antiga seja ele. Já as tecnologias informáticas são, sempre, as últimas disponíveis (ou, as penúltimas, já que, constantemente, as pessoas se tornam objeto de um frenesi de atualização, com receio de serem ultrapassadas pelo mercado de produção de objetos tecnológicos digitais). No que toca a estas (as tecnologias digitais), pode-se dizer que há um mínimo de clareza em sua utilização por parte dos criadores: seja por comodidade, seja por praticidade, a definição dos programas e das linguagens de programação não representa grande empecilho; nunca se soube de nenhum artista digital contemporâneo que tenha hesitado semanas na escolha de um programa ou de uma linguagem de programação, como fazia Flaubert diante de algumas de suas frases. De fato, essa escolha decorre de limitações do criador ou de sua equipe de apoio, no que diz respeito ao domínio de determinadas tecnologias; e o critério que impera, aí, é o da praticidade, ou seja, da possibilidade de uso imediato e bem-sucedido. Da mesma maneira, na literatura tradicional impressa e escrita, a escolha da língua empregada na criação nunca foi problema. Repetindo: há um mínimo de clareza na escolha e na utilização das tecnologias digitais por parte dos criadores contemporâneos. Contudo, o mesmo não ocorre com relação às técnicas e aos materiais 
literários disponíveis: em virtude dessa heterogeneidade irredutível entre os dois campos, não se sabe e nunca se saberá, com certeza, o quê (e como) será utilizado, dentro dessa tradição literária já milenar. Pelos menos até que já exista uma tradição literária digital, o que só ocorrerá certamente dentro de vários anos. Em suma, não há clareza quanto aos materiais e processos das tradições literárias a serem utilizados, além da óbvia matéria verbal, sem a qual ficaria impossível falar em literatura (logo adiante, faremos menção a alguns critérios básicos para circunscrever, com algum grau de certeza, o campo das literaturas digitais; entre eles, está certamente a importância que se vai atribuir à matéria verbal).

Assim, se não há um mínimo de clareza na escolha dos elementos literários a serem incorporados às criações literárias digitais, é fácil entender que também não haja no que provavelmente seja ainda mais crucial: o diálogo entre criação verbal e tecnologia informática. Em consequência disso, vemos aparecer uma quantidade considerável de criações que, de literária, têm apenas o título: poesia (e não poema, como seria mais correto) digital talvez seja o exemplo mais corrente, rótulo atribuído a criações que, de fato, quase nada têm de literário. Ora, houvesse consciência das relações possíveis, desejáveis (e, a contrapelo, inconsistentes, inaceitáveis) entre literatura e informática, certamente teríamos mais acerto na atribuição de gêneros que o autor sugere ou que propõe a crítica.

Diante disso tudo é que nos dispomos a apontar algumas criações digitais e emitir nosso julgamento acerca dos procedimentos inaugurados ou utilizados por elas. Porém, faremos isso sem perder de vista que a crítica literária, seja do meio digital ou do impresso, só ganha consistência e validade quando entrelaçada ao exercício da teoria, que é o de questionar os próprios pressupostos de julgamento da crítica. Falamos isso antes de tudo, por entendermos que uma das maiores contribuições das poéticas digitais contemporâneas é a abertura a meios, formas, códigos, retóricas, poéticas e materiais (sobretudo estes últimos!) que nunca antes haviam tido papel de destaque, em qualquer época da história das literaturas. Dito de outra maneira, a maioria das tentativas de sistematizar a literatura são feitas associando uma dentre várias perspectivas (culturalista, histórica, psicanalítica, política, ideológica etc.) à linguagem verbal (mas exclusivamente a ela!), como se nunca nenhum outro material, além da palavra, tivesse sido utilizado. Na delimitação do campo literário, feita por críticos e teóricos, confundia-se predominio com exclusividade da matéria verbal. Por conseguinte, quase sempre, as tentativas de propor conceitos e gêneros para as literaturas, passavam exclusivamente pelas estratégias associadas a essa matéria. Ora, nas últimas décadas, com as possibilidades abertas 
pelo digital, concretizou-se a utilização de diferentes elementos na criação literária. A informática nos fez capazes de empregar diversos meios (a internete, o computador, o telefone celular etc.), através da justaposição de distintas linguagens (a verbal, claro, mas também a icônica e a de programação, entre outras), o que tornou imediato o uso de elementos outros além do verbal: sons, músicas, imagens, vídeos, interatividades etc.

Com isso, rapidamente, os críticos da literatura, talvez até por comodidade, passaram a associar essa heterogeneidade inerente da criação digital ao verbivocovisual da poesia concreta. Nada mais equivocado - cabe dizer — e a explicação disso se vê facilmente, quando examinamos algumas tentativas de adaptar poemas concretos ao meio digital. Nem toda a indulgência com que se empregue qualquer teoria da transcriação intersemiótica daria conta de ver grande interesse nesses exercícios. É certo que o Concretismo chamou a atenção, muito acertadamente, para o fato de que o verbal foi sempre preponderante, mas nunca exclusivo na construção das literaturas. Mas é também claro que, em nenhum dos muitos escritos críticoteóricos dos mentores desse movimento, foram bem expostas e bem discutidas as relações entre técnicas (de criação) e tecnologias (dos meios de interação com os significantes criados). Eles, de fato, limitaram-se a explorar as relações conflituosas e, potencialmente, enriquecedoras entre diferentes linguagens, mas não perceberam que o problema estava em outro nível, esse das técnicas e das tecnologias.

Há ainda um aspecto que também merece consideração mais detida. A crítica e a teoria literária tradicionais, quando tentam (ainda que muito raramente!) pensar a emergência das literaturas digitais, no mais das vezes, é por meio de comentários isolados, desprendidos de qualquer esforço sério de sistematização. E, nesses casos, o que se faz é tentar ver num fenômeno a continuidade do outro. Em outras palavras, submetem as novas criações artísticas digitais praticamente aos mesmos critérios com que analisam as estratégias anteriores. Quer dizer, esperam ver nelas as mesmas práticas, os mesmos campos de possibilidades de que emergiram as literaturas orais/escritas/impressas. Não atentaram ainda para o fato de que novos signos em rotação, como diria Octavio Paz, não repetem necessariamente os efeitos estéticos consolidados por séculos de literatura com predomínio do verbal, e que as literaturas digitais estão impondo outra forma de entendermos suas poéticas, não só à luz de suas técnicas artísticas e estéticas específicas, mas, agora também, a partir de suas condições de contorno tecnológicas. Contudo, a situação é igualmente problemática do lado dos criadores literários, quando tentam ou mesmo quando nem tentam classificar, categorizar ou atribuir 
gêneros a suas criações digitais. Exemplo disso é a dificuldade em recuperarmos, numa simples busca na internete, os artistas que admitem estar elaborando criações literárias digitais: para escapar a problemas de classificação, muitos preferem a generalidade do termo arte digital. Há, assim, uma quase perfeita simetria entre criadores literários, de um lado, e críticos e teóricos, de outro: se estes não entenderam ainda o papel das tecnologias digitais no diálogo com as técnicas de criação verbal, aqueles ainda não atinaram com o papel da matéria verbal também como elemento de provocação e de instigação para as tecnologias digitais.

Assim, o que temos atualmente é um entrelaçamento, às vezes conflitante, harmonioso em outras, de retóricas, de códigos, de técnicas. E mesmo que a literatura esteja representada em cada um dessas criações literárias digitais por meio da palavra, não se pode mais estabelecer que seja esse o elemento definidor exclusivo de uma dada obra como literária. Em muitas das criações que serão mencionadas aqui, poderemos ver que, mesmo naquelas classificadas por seus autores como literárias digitais, a função da palavra não é mais a de inaugurar sozinha um mundo a ser fruído pelo leitor, mas sim a de reconfigurar-se, a própria palavra, em meio aos demais significantes (sons, imagens, interatividades etc.) na elaboração dos espaços de textualização (ou seja, de leitura).

Por isso tudo, uma sistematização teórica ainda não é totalmente realizável, neste momento (se é que um dia o será!); mas, como dizíamos acima, ela é também, ao mesmo tempo, incontornável. É justamente em cima dessa aporia que se tem de fazer a crítica às obras literárias digitais. E é essa aporia que, de fato, pode possibilitar, alimentar e até enriquecer a crítica feita às literaturas digitais! Dizendo de outro modo: se essa sistematização não é plenamente realizável, isso não é razão para não se perseguir um sistema crítico e teórico, ainda que assimptóticamente. E se a crítica e a teoria ainda não têm condições de erigir um sistema completo, coerente e acabado, ao menos podem propor tipologias que organizem minimamente os modos de escritas digitais. E, à moda de espelho, usá-los para repensar, deslocar, alterar seu próprio sistema. Nesse caso, os críticos e teóricos das literaturas digitais terão diante de si exatamente a mesma tarefa que, desde sempre, foi a dos que se debruçaram sobre as literaturas anteriores às digitais: olhar para seu próprio exercício de 
leitura e de teorização, a partir de seus objetos literários. Ou, como se pode aprender com Merleau-Ponty (em O Olho e o Espirito), devemos olhar nosso ofício com os olhos daquilo que pensamos olhar, ou seja, olharmos, com os olhos das obras, aquilo que ainda não estamos aparelhados para ver. Em nome dessas questões todas, selecionamos abaixo algumas obras digitais que revelam diferentes procedimentos de criação e, a partir deles, nos permitimos enunciar alguns juízos sobre as escritas digitais no Brasil, na atualidade. O que temos em vista, em todos os casos, é o que aprendemos com essas obras, e não quaisquer juízos que lhes pretenderíamos sobrepor. E é justamente a partir dos problemas levantados por elas que tentaremos esboçar alguma tipologia, mas uma tipologia aprendida diretamente da leitura de tais criações, nunca tirada de uma tradição artística ou estética prévia.

Assim, um primeiro problema, talvez o mais evidente, talvez mesmo $\mathbf{O}$ problema, quase nunca resolvido a contento, é o das relações entre tecnologia digital e matéria verbal (como já havíamos apontado acima). Com muita frequência, encontramos na internete criações que se utilizam de recursos técnicos do computador apenas para exibir e/ou ilustrar composições escritas, utilizando procedimentos que não incorporam, de fato, as lógicas digitais aos processos de criação, muito menos estabelecem um diálogo profundo entre digital e verbal. Estes ficam separados, dentro da criação, como se estivessem em compartimentos estanques. E muito menos buscam deslocar as lógicas digitais, acomodando-as à expressão literária. São projetos que, verdadeiramente, ainda não se deram conta das possibilidades de entrelaçamento, das complexidades dos diferentes significantes e linguagens postos à disposição pelas tecnologias informáticas. E uma das maneiras mais frequentes de se equivocar diante dessas relações entre digital e verbal, é não superar uma pretensa contraposição entre ambas, baseando a criação num falso antagonismo. É o caso das Seis propostas para o próximo milênio, de Gian Zelada (www.mamutemidia.com.br/6propostas/). Esta, como muitas outras, peca por fazer da falta de informação a estratégia (aparente, ao menos) de leitura que se impõe ao leitor, como se ele devesse e pudesse adivinhar o que tem de fazer com as interatividades da tela. É justo dizer que essas Seis propostas... trazem notas explicativas iniciais, mas nada nelas permite de fato manipular palavras e processos digitais em condições de igualdade. E, quando passamos para as telas interativas e programadas, o fosso entre palavras e significantes digitais não faz mais do que se aprofundar, a despeito das tentativas de propor claramente (aqui, sim) ao leitor uma possível relação entre a programação e as palavras que são exibidas com elas. 
Coisa distinta, mas igualmente problemática, ocorre com os assim chamados vídeopoemas, de que é bom exemplo Lâmina sobre a íris, de João e Adriana Versiani (www.youtube.com/watch?v=3Zw25OHg2fY). Talvez seja esse o tipo de criação poética em meio digital mais praticado hoje em dia, mas que se revela mais propriamente um fenômeno de comunicação (até mesmo de massas) do que propriamente uma construção artística que inaugure experiências estéticas mais elaboradas (para não falar da falta de entrelaçamento entre verbal e digital). Os vídeo-poemas pretendem o direito de levar o nome de poemas pelo simples fato de fazerem as imagens girarem em torno de palavras, sem que umas e outras consigam ir além da mera e simples justaposição. Estamos sem dúvida diante de algo muito mais ligado à tradição do vídeo-clipe, e mesmo à do cinema, do que propriamente uma obra que possa usar sem rebuços a classificação de literária. O que esperaríamos, nesse caso, é um objeto em que as tensões próprias da literatura seriam postas a funcionar em meio digital, alterando as lógicas de sentidos deste último.

Paralelamente a isso, vem a imensa quantidade de obras que apenas realizam a digitalização da literatura impressa. Um exemplo típico está em www.poesiadigital.com.br. Nesse caso, escritos absolutamente tradicionais não mantêm nenhuma correspondência mais profunda com o meio digital, apenas utilizam ferramentas digitais de editoração, em formato de livro impresso, de obras que seguem rigorosamente as mesmas lógicas do meio impresso. É o que também marca os Poemas de Sônia Van Dijck (www.soniavandijck.com/poemas.htm). Nesse caso, versos absolutamente tradicionais não mantêm nenhuma correspondência mais profunda com imagens (que, em si próprias, são nada interessantes); ambos são colocados lado a lado como se uma mão invisível da estética fosse criar uma possibilidade de diálogo entre eles, resolvendo as deficiências da criação artística. E, mais grave do que o problema citado acima, é o fato de que se trata de procedimentos de composição e de leitura que não guardam o menor diálogo com as possibilidades expressivas do meio digital; estão aí possivelmente apenas pela facilidade de divulgação propiciada pela internete. De fato, é muito comum que, quando fazem menção a literatura digital, quase sempre as pessoas queiram falar da mera transposição da literatura impressa para o ambiente digital. É claro que essa prática - a transposição de obras literárias de um meio para outro - é trabalho importante e fundamental, e tem resultado em inestimáveis fontes de pesquisas (caso das bibliotecas digitais). Mas, por motivos óbvios, deve ser classificada de literatura em meio digital, o que é coisa bem diferente. Nesses casos, os significantes da literatura não são transformados, sequer sofrem intervenções, quando transpostos; no máximo ficam armazenados dentro de um 
esquema hipertextual que, apenas esse, diferencia-se da lógica impressa. E mesmo as tentativas de utilizar a lógica das ligações hipertextuais, ou seja, da navegação pelas páginas HTML, trazem, quase sempre, limitações muito evidentes, como se vê em Hiper Livro, de Daniel Seda (eu.chez.com/hiperluv.htm). O hipertexto que ele traz nessa criação não deixa de ser interessante, mas não faz mais do que chamar a atenção para o meio e suas possibilidades, e não para a apropriação específica desse meio por parte do leitor. Já existem diferenças evidentes nos procedimentos de leitura, de um ponto de vista ergonômico, todavia os significantes ainda são os mesmos, ou melhor, atendem ao mesmo processo de significação da tradição impressa. Em idêntica situação estão os blogues literários (ou poéticos, como querem alguns). Neles, procedimentos de navegação hipertextual são acrescentados à matéria verbal, mas sem que esta seja, de alguma forma, alterada pelas lógicas do digital. Para elucidar isso que queremos dizer, seria útil explorar um trabalho que, embora já encare abertamente o desafio de atuar na região limítrofe e de contato dos diferentes significantes e das diferentes lógicas expressivas, ainda não consegue estabelecer uma via de mão dupla entre os elementos ligados à matéria verbal e aqueles advindos da informática, caso em que a leitura das palavras e as interações com a tela se dariam num único plano de sentidos. Trata-se de Sígnica: um balaio da era pós-verso (apesar do verso) (signica.vilabol.uol.com.br/home.htm), obra coletiva organizada por Omar Khouri e por Fábio Oliveira Nunes. Apesar de o próprio subtítulo do trabalho indicar uma proposital ou aparente falta de critério ou de unidade nos procedimentos composicionais e de fruição, há, de fato, coerência no modo como o digital é empregado, criando miscelâneas de autores e também de significantes (que não apenas se associam, mas que, nessa associação, também se reanimam).

Outro problema decorrente da falta de clareza nas relações entre tecnologia digital e matéria verbal diz respeito ao predomínio do imagético em detrimento do verbal, mesmo em criações que se intitulam explicitamente poesia on literatura digital. É o caso de logo logos lago algo (www.arteonline.arq.br/museu/poesiadigital/jorge.htm) de Jorge Luiz Antônio. Há uma única imagem na página, e ela concentra a atenção do leitor, sobretudo por suas cores berrantes e por seus movimentos (embora estes sejam poucos, repetitivos e monótonos). E os versos ajudam a focalizar a atenção do leitor sobre a imagem, por serem demasiadamente simples, de escasso interesse, mesmo se os consideramos apenas como criação verbal (já que nada na leitura deles, de fato, equilibra-se na tensão entre verbal e digital, como seria possível e desejável nesse tipo de obra). A bem da verdade, muitas criações autointituladas poesia digital não passam de criação visual, ainda que tenham grande interesse como arte gráfica, como é o 
caso dos Infopoemas de Melo e Castro. É certo que o poeta português não os criou para o meio digital, ainda que o tenha feito utilizando programas de computador, mas eles não trazem o que de mais relevante (e desafiador para quem busca empregar a matéria verbal) é dado pelo meio digital - a imersão no ambiente de leitura via interatividades. Ora, não é difícil aceitar que o caminho mais seguro para diferenciarmos o que repousa na ordem do literário daquilo que já se aproxima mais das artes visuais, é a colocação da palavra no centro do campo que se pretende tensionar, no centro do mundo que o criador quer fazer nascer para que um leitor o habite (ou de que tenha fruição). Mas vamos nos permitir colocar parcialmente em dúvida o que já insinuamos acima: será mesmo esse o caminho que nos permitirá continuar falando de literatura, diante da convivência da palavra com esses outros elementos? Talvez fosse mais adequado, para definir as literariedades digitais, deslocar e ampliar esse campo e partir, então, da noção de escrita (diretamente como aprendemos a usá-la, isto é, através de uma união íntima e originária entre a matéria verbal e nosso corpo). Porém, nesse caso, a escrita é empregada com elementos não verbais. Com o aprimoramento dessas técnicas e tecnologias de produção de significantes não verbais, e dependendo do campo expressivo escolhido pelo artista, esses elementos continuarão indiretamente a serviço do verbal, pois estarão diretamente a serviço da escrita, o que nos dará não uma certeza absoluta, mas, ao menos, indícios seguros de estarmos diante de literatura. E não se trata de nenhum golpe torneio argumentativo forçado! Estamos aqui seguindo a sugestão de Barthes, quando propõe que não se considere a linguística como um capítulo da semiologia, mas que se entenda esta como uma decorrência daquela. $\mathrm{O}$ pensador francês admite assim a predominância do verbal e nós, aqui, propomos o mesmo, apenas deslocando o eixo da matéria - as palavras — para a operação expressiva que em que elas se dão — a escrita -

Em A Escrita: Há futuro para a escrita?, Vilem Flusser propõe uma interessante distinção entre "poetas" e "criadores de novos modelos de experiência". Os primeiros estariam mais engajados com a renovação de uma linguagem (verbal) e os segundos mais preocupados em aprender e articular as linguagens e códigos não verbais para propor experiências estéticas. O primeiro grupo estaria mais para a poiesis e o segundo para a mímesis (dado que os códigos articulados por esse último grupo são mais próximos da representação da realidade, ou natureza, que os códigos verbais). Claro, o resumo que expomos aqui não é justo com as reflexões do filósofo tcheco que elabora esses argumentos em centenas de páginas, mas queremos aproveitar essa intuição de Flusser (mesmo que a apropriação seja feita grosso modo), para pensarmos em que medida nossa função, enquanto críticos de literatura, será 
ainda a de recuperar a hegemonia da poiesis diante desse mundo multicodificado. Claro, não podemos simplesmente aceitar essa separação dicotômica proposta por Flusser, assim como fica difícil concordar com ele quando diz, no mesmo livro, que, em breve, o verbal apenas servirá ao imagético e ao sonoro, invertendo exatamente o que propusemos mais acima. Porém, mesmo essa sua dicotomia pode nos ajudar a localizar o principal ponto da reformulação à qual a crítica literária precisa se submeter. Explicamos: mesmo diante de obras em que a poiesis e a mimesis (no sentido empregado por Flusser) não estejam tão marcadamente definidas - casos de criações como as de Wilton Azevedo (disponíveis em wiltonazevedo.tumblr.com/) e do grupo 1maginário, coordenado por Chico Marinho (1maginari0.blogspot.com/) —, talvez se deva, ainda assim, propor com um mínimo de precisão e segurança qual código serve mais ao outro, não como pressuposto ou fundamento da leitura, mas como consequência dela. Essa é a única maneira de intrometer-se como leitor em meio aos significantes digitais e fazê-los plenos de sentido, para nós e para os leitores de nossas leituras.

Contudo, no avançar destes últimos parágrafos, fomos deslizando imperceptivelmente de uma ordenação realizada a partir de problemas, para uma em que as qualidades das obras indicam o fio-condutor. E por qualidade devemos entender as possibilidades que elas abrem (ainda!) no tocante às relações entre verbal e digital. Uma vertente que tem de ser explorada obrigatoriamente é a que se refere aos diálogos das literaturas digitais com os vídeo-jogos. Obras com as de Joeser Álvarez permitem, em alguns casos, usos e explorações das interatividades como se elas fossem outro tipo de escrita dada ao leitor; também parecem aprimorar melhor a possibilidade de trabalhar com a heterogeneidade de elementos, ainda que submetida ao verbal. É o que temos em www.arteonline.arq.br/museu/netartwebart/joeser.htm, criação em que a simplicidade das imagens e dos procedimentos não deixa de prender a atenção e o interesse do leitor, criação em que os conteúdos semânticos das palavras estão tensionados pelo aparato digital, e este se torna mais um significante diante da presença daquelas. Não por coincidência, Álvarez tem também programado jogos, como o War Game ${ }^{2}$, em que o leitor poderia intervir num conflito falando, por correspondência ou telefone, com os senhores da guerra. Mas talvez um dos melhores exemplos de diálogo bem-sucedido com os vídeo-jogos seja a criação Palavrador

2 Estava disponível, ainda há uma ou duas semanas, no endereço www.enternet.com.br/LineAlvarez/wargame/wargame_.htm. 
(arquivo

disponível

para

baixar

em

docs.google.com/leaf?id=0B2gzgpiI8Ww0N2I4ZmNiMjMtN2RIYy00NGRkLWIzOWEtMz

RkNGEzMjEwYzA4\&hl=en_US), coordenada por Chico Marinho, em que a linguagem e o ambiente tridimensional desses jogos são submetido às linhas de força da matéria verbal, não só pela utilização de palavras, versos e poemas lidos, mas pela possibilidade de realizar os percursos pelos diferentes objetos ali colocados como se fossem um exercício de escrita. De fato, o propósito de Palavrador é de transformar a inscrição (mais do que entrada, pode-se dizer que é inscrição) do leitor nesse ambiente em uma escrita mesmo!

Todavia, indo além dos exemplos do melhor e do pior, como expusemos acima, no geral da literatura digital brasileira, há uma série de lacunas que ainda têm de ser superadas, para que se possa falar de um sistema literário e, em decorrência, de uma tradição literária digital. Não cremos que haja grandes deficiências na apreensão e no domínio de linguagens de programação e de processos digitais; talvez se possa mencionar apenas a necessidade de um mapeamento maior e mais elaborado de procedimentos ergonômicos para as telas, para que se possa evitar um indesejável obscurecimento dos processos interativos e automáticos. Isso evitaria o dissabor que traz a leitura das muitas obras digitais que se mostram extremamente hostis com o leitor, como se seu propósito fosse apenas repetir, tal qual um mantra, a frase de Brás Cubas: o maior defeito deste livro és tu, leitor. $\mathrm{O}$ que realmente faz falta se refere às literaturas anteriores ao digital: é preciso estudar toda a tradição literária, especialmente aqueles momentos em que há diálogos com outros meios e estratégias, como é o caso das criações visuais barrocas. Estas já foram objeto de pesquisas e estudos sofisticadíssimos, em Portugal, sobretudo por parte de Ana Hatherly, mas ainda têm frequentação muito rara no Brasil.

A consequência desse último problema, associado aos outros que apontamos acima, é que há muitos poucos criadores digitais, no Brasil, fazendo uma obra literária, obra no sentido de construção de uma trajetória de criações que se mescla à vida intelectual e pessoal do artista (no sentido com que falamos da totalidade obra de um escritor). Não há muitos nomes que poderiam ser arrolados. Há o nosso próprio caso, mas não somos exatamente os mais indicados para falar disso (exatamente como fez Machado de Assis em sua Notícia da atual literatura brasileira, de que nos inspiramos aqui). Há Wilton Azevedo (há uma antologia dele em e-storias.org/interacto/?category_name=videos), que tem buscado pôr em contato uma criação verbal muito próxima da literatura tradicional com vídeos, sons e interatividade típicas do digital, em obras como O livro de Sibila e Ata-me, entre muitas outras. André Vallias (vide 
www.andrevallias.com/), já há muito tempo, tem baseado suas criações digitais num interessante e rico diálogo com a tradição da poesia visual, especialmente com a poesia concreta, em obras como Nous n'avons pas compris Descartes, IO: analysis, Prthvî, The verse / De verso, Hexaemeron, A encantação pelo riso, TRAKLTAKT e ORATORIO. Álvaro Andrade Garcia, mesmo pendendo mais para as criações visuais animadas, mantém constante e instigador diálogo com a criação verbal (sendo ele também poeta, autor de versos tradicionais), no seu Sitio de Imaginação (www.ciclope.art.br/). Giselle Beiguelman tem trabalhado com meios móveis, editando vídeos captados em celulares e outros aparelhos portáteis; seu Desvirtual é certamente um marco na literatura digital brasileira, tanto no que se refere à criação, quanto no que diz respeito à reflexão teórica. É de justiça mencionar também Elson Froes (www.elsonfroes.com.br/): sua obra (certamente ele tem uma trajetória que deve ser considerada assim, como obra) gira predominantemente em torno da palavra, embora não pareça lidar bem, de forma justa e fértil, com as tensões e complexidades entre matéria verbal e tecnologia digital; tem hipertextos interessantes e bem elaborados, mas que não são fruto de uma escrita fundada nesses contrastes que nos interessam. Em Pop Box, por exemplo, há espaço para poesia visual, poesia sonora e poesia em verso, mas nada de poesia digital. Legitimamente, ele utiliza a tecnologia para dar continuidade a procedimentos e a padrões de escrita ainda caudatários da tradição impressa, mesmo quando imprime a elas movimento e interatividade (bem limitada). De toda maneira, não chega aos complexos diálogos que são possíveis quando entramos no campo da literatura digital (no caso dele, é muito mais o campo da literatura no digital). Contudo, como ocorre com toda lista, essa certamente traz ausências injustas, mas nos traz, no mínimo, uma ideia do pouco que vem sendo feito na criação literária digital em nosso país.

Do lado da crítica a essa produção literária digital, há quase nada a falar. Acima, já havíamos feito menção às dificuldades da crítica literária tradicional em lidar com a criação digital. $\mathrm{E}$ as novas gerações que vêm surgindo, já habituadas à internete, ainda não se aprofundaram suficientemente em seus objetos, nem em fundamentos teóricos mais sofisticados, nem em procedimentos metodológicos amadurecidos. Como consequência, a quase totalidade se deixa enfeitiçar muito facilmente por uma tecnofilia acrítica e prefere louvar blogues medíocres a apontar ou buscar outras possibilidades de exercícios efetivos de uma literatura digital. Uns poucos limitam-se ao trabalho importante, mas extremamente limitado de realizar recensões e registros diacrônicos de artistas e de obras, como é o caso de Jorge Luiz Antônio. 
Em suma, esta nossa empreitada, que é a de iniciar uma sistematização ou, ao menos, de organizarmo-nos em meio a tipologias, nos fez partir de problemas ordenados e deslizar pelas qualidades e defeitos das obras escolhidas, o que, sem sombra de dúvida, exige que reformulemos, mais adiante, os problemas discutidos no início. Esse é o trabalho incessante da crítica que se lança à sistematização de qualquer escrita literária, seja ou não digital. Antonio Candido, na introdução da sua Formação da Literatura Brasileira, ensina que fazer crítica é elaborar critérios que nos permitam o julgamento das obras; é exatamente o que estamos tentando fazer, desde alguns anos, respondendo a tal necessidade de tentar estabelecer critérios de leitura e de julgamento. Sendo assim, o trabalho ainda está por ser (re)feito... e sempre estará, sobretudo no tocante à literatura digital, pois seus signos em constante movimento e mutação nos submetem também a uma crítica em rotação. Mas isso, vale repetir, não é diferente para a crítica literária como um todo, dado que o literato sempre buscará tensionar a região limítrofe da linguagem em que se instala.

\section{REFERÊNCIAS CITADAS}

FLUSSER, Vílem. A Escrita: há futuro para a escrita? São Paulo: Annablume, 2010.

MERLEAU-PONTY. O Olho e o Espirito. Tradução: Paulo Neves e Maria Ermantina Pereira. São Paulo: Cosac \& Naify, 2004.

O Visivel e o Invisivel. Tradução de José Artur Gianotti e Armando Mora d’Oliveira. São Paulo: Perspectiva, 2005 Phénoménologie de la perception. Paris: Gallimard, 2008.

PAZ, Otávio. Signos em Rotação. São Paulo: Perspectiva, 1976. 